\title{
A study of bacterial pathogens and antibiotic susceptibility patterns in chronic suppurative otitis media
}

\author{
M R MOFATTEH ${ }^{1}$, F SHAHABIAN MOGHADDAM ${ }^{2}$, M YOUSEFI $^{3}$, M H NAMAEI $^{3}$ \\ ${ }^{1}$ Department of ENT, Faculty of Medicine, ${ }^{2}$ Faculty of Medicine, and ${ }^{3}$ Infectious Diseases Research Center, Birjand \\ University of Medical Sciences, Iran
}

\begin{abstract}
Objective: To assess the frequency of bacterial agents in chronic suppurative otitis media and the antibiotic susceptibility patterns of isolates among patients.

Methods: A total of 185 patients clinically diagnosed with chronic suppurative otitis media were interviewed and middle-ear effusion samples were collected using sterile swabs. All bacterial isolates were identified by conventional microbiological methods. Antibiotic susceptibility patterns of the isolates were determined by Kirby-Bauer disc diffusion.

Results: Staphylococci spp. (64.9 per cent) were the most prevalent bacteria isolated, followed by Klebsiella spp. (12.9 per cent) and Pseudomonas aeruginosa (10.3 per cent). The most effective antibiotic for treatment of bacterial chronic suppurative otitis media was ciprofloxacin. Statistical analysis showed no significant difference in bacterial infestations among chronic suppurative otitis media patients and the antimicrobial susceptibility patterns of the bacterial isolates based on gender and age $(p>0.05)$.

Conclusion: Our findings highlight the importance of a continuous and periodic evaluation of the bacteriological profile and antibiotic susceptibility patterns in chronic suppurative otitis media patients for efficacious treatment of the infection.
\end{abstract}

Key words: Otitis Media; Suppurative; Bacterial Infections; Anti-Bacterial Agents

\section{Introduction}

Chronic suppurative otitis media (CSOM) remains one of the most common childhood diseases, prevalent mostly in developing countries. ${ }^{1,2}$ The infection is characterised by chronic inflammation of the middle ear and mastoid cavity, with tympanic membrane perforation. Chronic suppurative otitis media most often occurs in the first 6 years of life, and contributes to a significant disease burden worldwide, estimated at $65-330$ million people, with 28000 deaths per annum. ${ }^{3,4}$

Chronic suppurative otitis media has a profound impact on society in terms of hearing, and can have dangerous adverse effects in the absence of timely intervention. Many of these complications have been reduced to a greater extent with the invention of antimicrobial agents. Nevertheless, overuse of antibiotics can lead to the emergence of organisms that are resistant to the commonly used drugs. ${ }^{5-7}$ The control of CSOM poses a great therapeutic challenge given its recurrent nature and the development of resistant pathogenic organisms. Knowledge of the common causative organisms is essential for efficacious treatment of this infection. ${ }^{8,9}$
Most of the microbiological studies on CSOM have shown that the common bacteria found in CSOM are Escherichia coli, Pseudomonas aeruginosa, Staphylococcus aureus, Proteus spp. and Klebsiella spp., with methicillin-resistant $S$ aureus (MRSA) isolated in some cases. However, the type of bacteria associated with CSOM varies depending on the geographical area and other factors. ${ }^{9,10}$

It is important to know the major bacterial aetiologies of CSOM and their antibiotic susceptibility patterns, both for selection of the most appropriate treatment regimen and prevention of the emergence of resistant strains. This study aimed to evaluate the bacteriological profiles and antibiotic sensitivity patterns of CSOM patients admitted to the ENT clinic of Birjand Imam Reza Hospital, Iran.

\section{Materials and methods}

\section{Study population}

This cross-sectional descriptive-analytical study comprised a total of 185 patients clinically diagnosed with 
CSOM who were admitted to the ENT clinic of Birjand Imam Reza Hospital. These patients had received no antibiotic treatment during the previous 3 days, and had not suffered any otitis externa or trauma in the related area. Chronic suppurative otitis media was defined as otorrhoea through a perforated tympanic membrane, present for at least two to six weeks. ${ }^{4,11}$

Ethical committee approval was obtained before starting the study. In addition, all 185 enrolled patients signed informed consent forms.

\section{Sample collection}

Middle-ear discharge was collected from the patients, by an ENT specialist, under strict aseptic precautions using sterile swabs, after cleaning external auditory canal with a spirit swab. The swab samples were placed on thioglycollate broth media and immediately sent to the microbiology laboratory for bacterial studies.

\section{Identification of bacterial isolates}

The swab samples were cultured on 5 per cent sheep blood agar, eosin methylene blue agar and chocolate agar for isolation of aerobic bacteria, and incubated aerobically at $37^{\circ} \mathrm{C}$ for $24-48$ hours. The isolates grown were identified according to standard microbiological and biochemical methods. ${ }^{12}$

\section{Antibiotic susceptibility of bacterial isolates}

The antibiotic resistance profile of the isolates was determined by the Kirby-Bauer disc diffusion method using Mast Group discs (Bootle, UK), and the results were interpreted according to Clinical and Laboratory Standards Institute guidelines. The antibiotic discs used included: amoxicillin, ciprofloxacin, erythromycin, clindamycin, co-trimoxazole, cefoxitin, cephalexin, cefixime, ceftazidime, ceftriaxone, cefazolin, amikacin, gentamicin and imipenem. For quality controls, the various standard strains were used based on Clinical and Laboratory Standards Institute recommendations. ${ }^{13}$

\section{Statistical analysis}

The data were analysed with the Pearson chi-square test, using SPSS $^{\circledR}$ statistical software (version 21), to evaluate the statistical significance of associations between potential variables. $P$ values of less than 0.05 were considered to be significant.

\section{Results}

A total of 185 patients with CSOM were investigated in this study. The mean age of patients was 36.22 years (range, 4-86 years), and the majority of the patients (22.7 per cent) were aged $21-30$ years. Of the patients, 40.5 per cent were male and 59.5 per cent were female.

\section{Bacterial isolates}

Of the 185 ear swabs processed, bacterial growth was found in 180 samples (97.3 per cent), while 5 samples (2.7 per cent) showed no growth. The results revealed that staphylococci spp. were the most prevalent bacteria

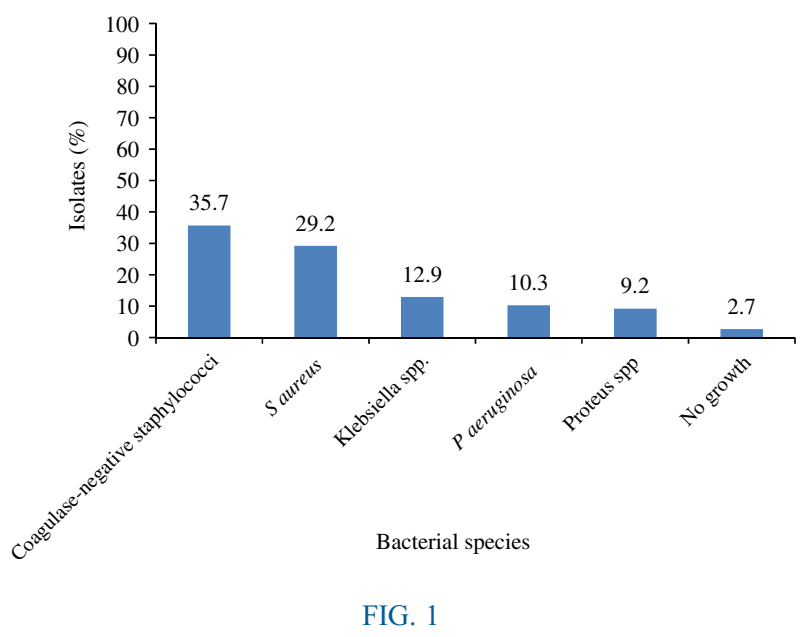

Frequency of bacterial species distribution among chronic suppurative otitis media patients.

isolated (64.9 per cent), followed by Klebsiella spp. (12.9 per cent) (Figure 1). Coagulase-negative staphylococci were the most frequently isolated bacteria from males ( 25 isolates from 75 cases, $33.3 \%$ ) and females (41 isolates from 110 cases, 37.2\%).

Statistical analysis indicated no significant difference between the type of bacteria causing CSOM and gender $(p=0.91)$. The highest frequency of bacteria isolated from patients belonged to those in the 21-30-year age group (22.7 per cent). There was no significant difference between the type of bacteria isolated and patient age ( $p=$ $0.49)$. The frequency of bacteria isolated from the patients based on age and gender is shown in Table I.

\section{Antibiotic susceptibility}

In our study, $S$ aureus isolates demonstrated ceftazidime resistance in 96.2 per cent of cases and oxacillin (MRSA) resistance in 93.9 per cent of cases. In addition, there was high resistance of coagulase-negative staphylococci isolates to oxacillin (91.7 per cent) and cefixime (75.7 per cent). Staphylococci spp. showed high rates of susceptibility to clindamycin and cephalexin (Table II). P aeruginosa isolates were completely resistant to co-trimoxazole and cefixime, but the isolates showed high sensitivity to imipenem (100 per cent), ciprofloxacin (93.7 per cent) and amikacin (93.7 per cent). Furthermore, Proteus and Klebsiella spp. exhibited relatively high resistance to cephalexin and cefixime. The organisms were highly sensitive to ciprofloxacin and amikacin (Table III).

Overall, the most effective antibiotic for CSOM treatment was ciprofloxacin. However, statistical analysis showed no significant differences in the antimicrobial susceptibility patterns of the bacteria isolated from CSOM patients based on patient age and gender $(p>0.05)$.

\section{Discussion}

Chronic suppurative otitis media is one of the most common hearing problems, with approximately a 5 


\begin{tabular}{|c|c|c|c|c|c|c|c|c|}
\hline \multicolumn{9}{|c|}{$\begin{array}{l}\text { TABLE I } \\
\text { ERIAL ISOLATES BY AGE AND GEN }\end{array}$} \\
\hline Variables & $\begin{array}{l}\text { Coagulase-negative } \\
\text { staphylococci }\end{array}$ & $S$ aureus & $P$ aeruginosa & $\begin{array}{l}\text { Klebsiella } \\
\text { spp. }\end{array}$ & $\begin{array}{l}\text { Proteus } \\
\text { spp. }\end{array}$ & $\begin{array}{l}\text { No } \\
\text { growth }\end{array}$ & Total & $P$-value* \\
\hline Gender & & & & & & & & 0.91 \\
\hline - Male & 25 (37.9) & $22(40.7)$ & $9(47.4)$ & $9(37.5)$ & $8(47.1)$ & $2(40)$ & $75(40.5)$ & \\
\hline - Female & $41(62.1)$ & $32(59.3)$ & $10(52.6)$ & $15(62.5)$ & $9(52.9)$ & $3(60)$ & $110(59.9)$ & \\
\hline Age (years) & & & & & & & & \\
\hline$-\leq 10$ & $0(0)$ & 1 (1.9) & $2(10.5)$ & $1(4.2)$ & $0(0)$ & $2(40)$ & $6(3.2)$ & 0.49 \\
\hline$-11-20$ & $10(15.2)$ & $11(20.4)$ & $2(10.5)$ & $2(8.3)$ & $4(23.5)$ & $0(0)$ & 29 (15.7) & \\
\hline$-21-30$ & $15(22.7)$ & 14 (25.9) & $4(21.1)$ & $5(20.8)$ & $4(23.5)$ & $0(0)$ & $42(22.7)$ & \\
\hline$-31-40$ & $8(12.1)$ & $8(14.8)$ & $3(15.8)$ & $5(20.8)$ & 3 (17.6) & $0(0)$ & 27 (14.6) & \\
\hline$-41-50$ & $17(25.8)$ & 9 (16.7) & $6(31.6)$ & $3(12.5)$ & $2(11.8)$ & $2(40)$ & $39(21.1)$ & \\
\hline$-51-60$ & 9 (13.6) & $3(5.6)$ & $2(10.5)$ & $5(20.8)$ & 3 (17.6) & $1(20)$ & $23(12.4)$ & \\
\hline$->60$ & 7 (10.6) & $8(14.8)$ & $0(0)$ & $3(12.5)$ & $1(5.9)$ & $0(0)$ & $19(10.3)$ & \\
\hline
\end{tabular}

Data represent numbers (and percentages) of patients, unless indicated otherwise. ${ }^{*} P$ values obtained by Pearson chi-square test. $\mathrm{CSOM}=$ chronic suppurative otitis media

per cent global incidence, and is particularly prevalent in developing countries. ${ }^{7,14}$ Chronic suppurative otitis media can cause many complications, including mastoiditis and meningitis, if not treated properly. Therefore, identification of the causative organisms is essential for proper management of CSOM. ${ }^{4,5}$

In our study, bacterial growth was seen in 97.3 per cent of CSOM cases, while five of the samples (2.7 per cent) showed no growth. The results of the current study are in line with the results of other research. ${ }^{5,15}$ Our study showed that staphylococci spp. were the most common bacteria isolated in CSOM, followed by Klebsiella spp. and P aeruginosa, which is in line with reports of some other studies in different parts of the world. ${ }^{2,16}$ However, other researchers have reported that $P$ aeruginosa are the most common isolated pathogenic bacteria in CSOM patients. ${ }^{4,7}$ It is noteworthy that very few studies have been conducted in this field in Iran. In a previous study, $S$ aureus was the most common aerobic isolate in CSOM. ${ }^{17}$ The differences in the spectra of bacteria causing CSOM imply that sole reliance on empirical antimicrobial therapy is not appropriate for effective treatment of affected patients.

The gender and age analysis of this study showed a variation in the ratio of suspected CSOM patients and

\begin{tabular}{lcc}
\multicolumn{3}{c}{ TABLE II } \\
\multicolumn{1}{c}{$\begin{array}{c}\text { RATES OF ANTIBIOTIC RESISTANCE IN } \\
\text { STAPHYLOCOCCI SPECIES }\end{array}$} \\
\hline Antibiotic & $\begin{array}{c}\text { S aureus } \\
(\%)\end{array}$ & $\begin{array}{c}\text { Coagulase-negative } \\
\text { staphylococci (\%) }\end{array}$ \\
\hline Amoxicillin & 90 & 88 \\
Ciprofloxacin & 13.3 & 10.4 \\
Erythromycin & 16.2 & 32.1 \\
Clindamycin & 11.8 & 8.3 \\
Co-trimoxazole & 15 & 17 \\
Oxacillin & 93.9 & 91.7 \\
Cephalexin & 12.8 & 12.5 \\
Cefixime & 91.7 & 75.7 \\
Ceftazidime & 96.2 & - \\
Ceftriaxone & 32 & - \\
Cefazolin & 26.7 & - \\
\hline
\end{tabular}

their bacterial infestations. The highest numbers of suspected CSOM patients were aged 21-30 years and the highest bacterial infestations were also found in this age group. Loy et al. showed an increased prevalence of CSOM in those aged 31-40 years. ${ }^{9}$ In another study, the highest numbers of cases and bacterial infestations among CSOM patients were seen in the 11-20-year age group. ${ }^{16}$ In contrast, numerous studies have found that the majority of CSOM patients were aged less than 20 years. ${ }^{4,18}$

In our study, there was a dominancy of female compared to male CSOM patients, which is consistent with some other studies. ${ }^{4,9}$ However, statistical analysis indicated that there were no significant differences between bacterial infestations among the patients in terms of gender or age.

Antibiotic susceptibility patterns serve as a useful guideline for choosing the appropriate antibiotic for CSOM treatment. In the present study, the highest antibiotic resistance of $S$ aureus isolates was observed for ceftazidime, followed by oxacillin. A high rate of MRSA was observed in our study, similar to other studies in various countries across the world. ${ }^{19-21}$ However, some researchers have observed a lower percentage of MRSA in CSOM patients. ${ }^{2,22}$ The high incidence of MRSA in our study was not surprising to us,

\begin{tabular}{lccc}
\multicolumn{4}{c}{ TABLE III } \\
\multicolumn{4}{c}{ RATES OF } \\
ANTIBIOTIC RESISTANCE IN GRAM- \\
NEGATIVE ISOLATES
\end{tabular}


because the patients had undergone several courses of antibiotic therapy.

The rising prevalence of antibiotic resistance (especially in developing countries) can be attributed to the overuse and incorrect use of antibiotics. Although the $S$ aureus isolates in our study were relatively sensitive to certain cephalosporins, MRSA strains should be considered resistant to these agents (with the exception of cephalosporins with anti-MRSA activity), based on Clinical and Laboratory Standards Institute guidelines. ${ }^{13}$ The current study found a high resistance of coagulase-negative staphylococci isolates to oxacillin and cefixime. In our study, staphylococci spp. showed high rates of susceptibility to clindamycin, cephalexin and ciprofloxacin. The sensitivity of staphylococci spp. to ciprofloxacin in our study is consistent with other reports; most investigators also reported a high sensitivity rate for staphylococci spp. to fluoroquinolones. ${ }^{17,23}$

In our study, $P$ aeruginosa isolates showed complete resistance to co-trimoxazole and cefixime, but the isolates were highly sensitive to imipenem, ciprofloxacin and amikacin. This is supported by previous studies, such as those by Agrawal et al., ${ }^{19}$ and Nazir and Kadri. ${ }^{4}$ Additionally, the present study indicated that Proteus and Klebsiella spp. showed relatively high resistance to cephalexin and cefixime, and these pathogens showed a high sensitivity to ciprofloxacin and amikacin. In a previous study, amikacin was found to be the most effective antibiotic against Proteus and Klebsiella spp. isolated from CSOM patients, followed by imipenem, piperacillin-tazobactam and ciprofloxacin. ${ }^{4}$

- Knowledge of chronic suppurative otitis media (CSOM) bacterial aetiologies and antibiotic susceptibility patterns is essential for efficacious management

- Staphylococci and Klebsiella spp., followed by $P$ aeruginosa, were the most common causative bacterial agents in CSOM

- The high incidence rate of methicillinresistant $S$ aureus among CSOM patients is concerning

- Ciprofloxacin was the most effective antibiotic for bacterial CSOM treatment

Overall, our study showed no significant differences in the antimicrobial susceptibility patterns of the bacteria isolated from CSOM patients based on patient age and gender. The variation in the antimicrobial resistance profiles of bacteria causing CSOM in various studies may be related to differences in geography, local antimicrobial prescribing practices and the prevalence of resistant bacterial strains.

\section{Conclusion}

Our findings highlight the importance of staphylococci and Klebsiella spp., followed by $P$ aeruginosa, as the most common causative bacterial agents of CSOM. The high incidence rate of MRSA among CSOM patients is a cause for concern. The use of betalactam antibiotics as an empirical therapy is not recommended when $S$ aureus infection is suspected. Ciprofloxacin was shown to be the most effective antibiotic, with high sensitivities for the most commonly isolated bacteria associated with CSOM.

\section{Acknowledgement}

This research was supported by Birjand University of Medical Sciences, Iran (grant number: 575).

References

1 Neeff M, Biswas K, Hoggard M, Taylor MW, Douglas R. Molecular microbiological profile of chronic suppurative otitis media. J Clin Microbiol 2016;54:2538-46

2 Vaidya K, Madhup SK, Shrestha BL, Gautam A, Tuladha NR. Bacteriological and mycological profile of chronic suppurative otitis media among patients visiting Dhulikhel Hospital. Ann Clin Chem Lab Med 2015;1:37-41

3 Sengodan R, Sukumar N. Microbiological profile of chronic suppurative otitis media (CSOM) in a tertiary care hospital. Int J Bioassays 2017;6:5355-9

4 Nazir A, Kadri SM. Aerobic bacteriology of chronic suppurative otitis media: a hospital based study. Int J Res Med Sci 2014;2: 1521-5

5 Prakash M, Lakshmi K, Anuraha S, Swathi GN. Bacteriological profile and their antibiotic susceptibility pattern of cases of chronic suppurative otitis media. Asian J Pharm Clin Res 2013;6:210-12

6 Abdelshafy I, Haleem A, Khalil Y, Ghazal A, Gaballah A. Microbiology of chronic suppurative otitis media, study of the role of bacterial biofilm and fungal infection. $J$ Otolaryngol ENT Res 2015;3:00051

7 Orji F, Dike B. Observations on the current bacteriological profile of chronic suppurative otitis media in South Eastern Nigeria. Ann Med Health Sci Res 2015;5:124-8

8 Kumar S, Sharma R, Saxena A, Pandey A, Gautam P, Taneja V. Bacterial flora of infected unsafe CSOM. Indian J Otol 2012;18: 208-11

9 Loy A, Tan A, Lu P. Microbiology of chronic suppurative otitis media in Singapore. Singapore Med J 2002;43:296-9

10 Kumar R, Srivastava P, Sharma M, Rishi S, Nirwan S, Hemwaniand $\mathrm{K}$. Isolation and antimicrobial sensitivity profile of bacterial agents in chronic suppurative otitis media patients at NIMS Hospital. Jaipur IJPBS 2013;3:265-9

11 Verhoeff M, van der Veen EL, Rovers MM, Sanders EA, Schilder AG. Chronic suppurative otitis media: a review. Int $J$ Pediatr Otorhinolaryngol 2006;70:1-12

12 Winn WC Jr, Allen SD, Janda WM, Koneman E, Procop G, Schreckenberger P et al. Koneman's Color Atlas and Textbook of Diagnostic Microbiology, 6th edn. Philadelphia: Lippincott Williams \& Wilkins, 2005

13 Clinical and Laboratory Standards Institute. Performance Standards for Antimicrobial Susceptibility Testing; TwentyFourth Informational Supplement. CLSI document M100-S24. Wayne, PA: Clinical and Laboratory Standards Institute, 2014

14 Afolabi O, Salaudeen A, Ologe F, Nwabuisi C, Nwawolo C. Pattern of bacterial isolates in the middle ear discharge of patients with chronic suppurative otitis media in a tertiary hospital in north central Nigeria. Afr Health Sci 2012;12:362-7

15 Agrawal A, Kumar D, Goyal A, Goyal S, Singh N, Khandelwal G. Microbiological profile and their antimicrobial sensitivity pattern in patients of otitis media with ear discharge. Indian $J$ Otol 2013;19:5-8

16 Latif A. Prevalence of bacteria in chronic suppurative otitis media patients and their sensitivity patterns against various antibiotics in human population of Gilgit. Pakistan J Zool 2013;45: $1647-53$ 
17 Nia KM, Sepehri G, Khatmi H, Shakibaie M. Isolation and antimicrobial susceptibility of bacteria from chronic suppurative otitis media patients in Kerman, Iran. Iran Red Crescent Med $J$ 2011;13:891-4

18 Shyamala R, Reddy PS. The study of bacteriological agents of chronic suppurative otitis media--aerobic culture and evaluation. J Microbiol Biotechnol Res 2017;2:152-62

19 Agrawal R, Khatri P, Parihar R, Shah H. Microbial assessment of chronic suppurative otitis media in a tertiary care center of Rajasthan. Int J Health Sci Res 2017;7:120-6

$20 \mathrm{Yu}$ YI, Cha CI, Lee IY, Byun JY, Cho JS. Current bacteriology of chronic suppurative otitis media. Korean J Otorhinolaryngol Head Neck Surg 2004;47:607-11

21 Rawat A, Goyal R. A study of bacterial profile and antibiotic susceptibility pattern of chronic suppurative otitis media (CSOM). Int J Curr Microbiol App Sci 2015;4:23-7

22 Iqbal K, Khan MI, Satti L. Microbiology of chronic suppurative otitis media: experience at Dera Ismail Khan. Gomal J Med Sci 2012;9:189-93
23 de Miguel MI, Del Rosario QC, Bolaños RM, Ramos MA. Aetiology and therapeutic considerations in chronic otitis media. Analysis of a 5 year period [in Spanish]. Acta Otorrinolaringol Esp 2005;56:459-62

Address for correspondence:

Dr Mohammad Hasan Namaei,

Infectious Diseases Research Center,

Birjand University of Medical Sciences,

Birjand, Iran

E-mail: mhnamaei@gmail.com

Dr M H Namaei takes responsibility for the integrity of the content of the paper

Competing interests: None declared 